\title{
Is the reno-protective effect of valsartan dose dependent? A comparative study of 80 and $160 \mathrm{mg}$ day $^{-1}$
}

\author{
Tetsunori Saikawa $^{1}$, Jun Sasaki ${ }^{2}$, Sadayoshi Biro ${ }^{3}$, Suminori Kono ${ }^{4}$, Takatoshi Otonari ${ }^{5}$ and Yoshiyuki Ikeda $^{6}$, \\ DDV investigators ${ }^{7}$
}

Whether the reno-protective effect of angiotensin receptor blockers is dose dependent is unknown for the Japanese population. We sought to elucidate the dose-dependent reno-protective effects of valsartan in Japanese hypertensive patients with albuminuria. This was a multi-center, open-label, parallel-group trial. A total of 181 patients were randomized to receive either $80(n=89)$ or $160 \mathrm{mg} \mathrm{day}^{-1}(n=92)$ of valsartan for 24 weeks. Then, the effects on blood pressure, urinary albumin excretion (UAE), type IV collagen and $\beta_{2}$-microglobulin ( $\beta 2 M G$ ) were determined. Systolic and diastolic blood pressures decreased substantially by almost the same extent in the low-dose and high-dose groups, showing no inter-group difference during the treatment. The UAE value decreased significantly by $35 \%$ in both groups. Urinary excretion of $\beta 2 \mathrm{MG}$ was significantly decreased in the high-dose group (17\%), but not in the low-dose group (13\%), although the decrease was not significantly different between the two groups $(P=0.74)$. Urinary excretion of type IV collagen decreased non-significantly by $10 \%$ in the low-dose group and by $8 \%$ in the high-dose group, showing no significant inter-group difference $(P=0.78)$. Low $\left(80 \mathrm{mg}^{-1} \mathrm{yy}^{-1}\right)$ and high $\left(160 \mathrm{mg} \mathrm{day}^{-1}\right)$ doses of valsartan showed a similar effect of lowering blood pressure. The high dose of valsartan resulted in

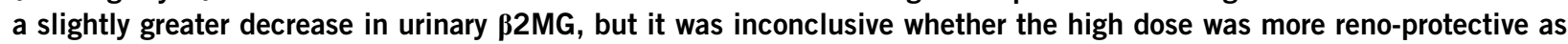
compared with the low dose.

Hypertension Research (2010) 33, 886-891; doi:10.1038/hr.2010.108; published online 17 June 2010

Keywords: albumin; dose effect; renal protection; type IV collagen; valsartan

\section{INTRODUCTION}

The role of angiotensin receptor blockers (ARBs) and angiotensin I-converting enzyme inhibitors (ACEIs) in the treatment of hypertension has been established in recent years. ${ }^{1-6}$ The blood pressurelowering action of ARBs and ACEIs has been shown to be dose dependent. Oparil et al. ${ }^{7}$ prescribed valsartan $(20,80,160$ or $320 \mathrm{mg}$ daily) to patients with essential hypertension and studied the efficacy and safety of valsartan compared with placebo in the treatment of hypertension. A dose-response effect on the reduction of blood pressure was observed with doses $\geqslant 80 \mathrm{mg}$, although no difference was seen in the response rate between placebo and $20 \mathrm{mg}$ daily dose of valsartan. Neutel et al. ${ }^{8}$ investigated the effect of valsartan $(20,80,160$ and $320 \mathrm{mg}$ daily) on blood pressure. A dose-dependent reduction of blood pressure over $24 \mathrm{~h}$ and a greater reduction of blood pressure were noted for doses of valsartan $\geqslant 80 \mathrm{mg}$ compared with $20 \mathrm{mg}$. Other similar studies also showed a dose-dependent effect on the ability of different ARBs to lower blood pressure. ${ }^{9,10}$
Several studies have demonstrated beneficial effects of ARBs on renal function, proteinuria and albuminuria, ${ }^{11-13}$ and the effects on micro-albuminuria may not correspond to blood levels of albumin. ${ }^{14}$ Suzuki et $a .^{15}$ reported a significant decrease in urinary albumin excretion (UAE) with valsartan $\left(40 \mathrm{mg} \mathrm{day}^{-1}\right)$ therapy, but there was little change in blood pressure in patients with diabetic nephropathy. A markedly high dose of an ARB, such as valsartan (640 mg daily) and candesartan (64 mg daily), resulted in a reduction in UAE without a further reduction in blood pressure. ${ }^{16,17}$ Recent experimental studies also reported that a very high dose of valsartan provided reno-protection independent of the effect on blood pressure in a rat model of type 2 diabetic nephropathy. ${ }^{18}$ Whether or not the reno-protective effect of valsartan is dose dependent has not been addressed in Japanese patients. In this study, we investigated the reno-protective effect of valsartan (80 or $160 \mathrm{mg} \mathrm{day}^{-1}$ ) in Japanese patients with essential hypertension by means of a randomized trial.

${ }^{1}$ Department of Clinical Examination and Diagnostics, Oita University, Oita, Japan; ${ }^{2}$ Department of Clinical Examination and Epidemiology, International University of Health and Welfare, Graduate School of Public Health Medicine, Fukuoka, Japan; ${ }^{3}$ Tsukasa Hospital, Kagoshima, Japan; ${ }^{4}$ Department of Preventive Medicine, Kyushu University Faculty of Medical Sciences, Fukuoka, Japan; ${ }^{5}$ Otonari Clinic, Fukuoka, Japan and ${ }^{6}$ Togo Hospital, Kagoshima, Japan

${ }^{7}$ Members of the study group are listed in the Appendix.

Correspondence: Professor T Saikawa, Department of Clinical Examination and Diagnostics, Oita University, Oita, Japan.

E-mail: saikawa@med.oita-u.ac.jp

Received 13 December 2009; revised 4 April 2010; accepted 7 April 2010; published online 17 June 2010 


\section{METHODS}

\section{Patients}

Patients were recruited from 34 clinics and hospitals in Kyushu Island, Japan, between January 2006 and December 2007. The study subjects were male and female outpatients with systolic blood pressures of $140-159 \mathrm{~mm} \mathrm{Hg}$ and/or diastolic blood pressure of $\geqslant 90 \mathrm{~mm} \mathrm{Hg}$, regardless of medication status. The subjects were aged 20 years or older and had a UAE of 10-1000 mg per g Cr. Patients with any of the following conditions were excluded: (1) secondary

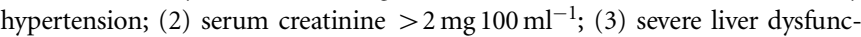
tion; (4) recent acute myocardial infarction or stroke ( $<6$ months); (5) use of ACEIs or ARBs in the past 6 months; (6) allergy to valsartan; and (7) study physician's assessment of inappropriateness for participation.

\section{Study design}

This was a multi-center, open-label, parallel-group trial. Eligible patients were enrolled at the central registration center and were randomized to receive either of two doses of valsartan $\left(80 \mathrm{or} 160 \mathrm{mg} \mathrm{day}^{-1}\right.$ ), which are currently approved in Japan. A computer-generated list of 220 random assignments was prepared by a statistician at the registration center using the random permutation block method with equal assignments to the two treatment groups. The first 200 assignments were created in two blocks of 100 random assignments each, and the last 20 assignments were generated in two blocks of 10 random assignments each for supplemental registration. Allocation to each treatment was made according to the sequence of the randomization list, which was kept confidential throughout the study period.

After obtaining informed consent, study physicians reported eligible patients to the registration center by fax and were informed of the assigned dose during the pre-study period. All study physicians followed the allocation correctly. The treatment period was preceded by a trial period, without blood pressurelowering agents, of 2-4 weeks; an interval chosen to correspond to the typical time between clinic visits.

Concomitant use of ARBs other than valsartan and ACEIs was prohibited during the study. Use of a small dose of diuretics and calcium antagonists was permitted when the target blood pressure level, as defined by the Japanese Society of Hypertension, was not achieved after 8-12 weeks of treatment with valsartan. Diet and exercise were not specifically mandated. Agents prescribed before enrollment were permitted on the condition that the doses were not changed during the study. Adherence to the study drug was assessed by asking patients to report their use of the assigned dose at weeks 12 and 24 with four options regarding drug use during the interval between clinic visits (daily, 5-6 days per week, 3-4 days per week and 1-2 days per week). Daily use or 5-6 days-per-week use was defined as good adherence. The study protocol was reviewed and approved by the ethics committee of each institution.

\section{Blood pressure measurements}

Systolic and diastolic blood pressures were measured by an automatic apparatus (Omron HEM-1000), which was provided for each participating clinic or hospital by the central administration office. Measurements were repeated thrice with patients sitting on a chair for at least $5 \mathrm{~min}$ in a relaxed position. The second and third readings were averaged and adopted as the measurements for use.

\section{Laboratory measurements}

Blood and urine samples were collected after an overnight fast at baseline and after 12 and 24 weeks of treatment. A 10-ml sample of venous blood was drawn for the determination of serum creatinine and blood urea nitrogen (BUN) levels. A 10-ml sample of urine was collected for the determination of UAE, type IV collagen and $\beta_{2}$-microglobulin ( $\beta 2 \mathrm{MG}$ ) levels. All determinations were performed at an external laboratory (SRL, Hachiohji, Japan) where the biochemical measurements under study were routinely under quality-control procedures. All results of the measurements were forwarded to the study physicians within 3 working days.

\section{Effectiveness outcomes}

The primary effectiveness outcome measures were changes in UAE, type IV collagen, $\beta 2 \mathrm{MG}$, blood pressure, serum creatinine and BUN levels.

\section{Tolerability outcomes}

Tolerability was assessed at each visit and included adverse events either spontaneously reported or elicited by questioning, physical examination findings, and clinical laboratory test results. Study physicians rated the causal relationship of adverse events to study medication as unrelated, suspected or probable. These ratings were finalized by the Safety Monitoring Committee in a blinded manner. Serious adverse events were defined as any untoward medical conditions that resulted in death, hospitalization, life-threatening condition or birth defect.

Abnormal laboratory test results were defined as values $>1.5$ times the upper limit of the reference range.

\section{Statistical analysis}

Descriptive data are presented as the mean \pm s.d. value unless otherwise specified. Means and proportions were compared between the two groups using an unpaired $t$-test and Fisher's exact test, respectively. Serum creatinine, UAE, type IV collagen and $\beta 2 \mathrm{MG}$ levels were skewed to higher values, and medians and inter-quartile ranges (25th and 75th percentiles) were presented for the baseline comparison by the Wilcoxon rank sum test. The values for serum creatinine, UAE, type IV collagen and $\beta 2 \mathrm{MG}$ levels were transformed to natural logarithms, and their geometric means were obtained. Exponentiation of the mean of the difference in the log-transformed values before and after the treatment corresponded to the percent change after treatment. Inter-group comparison of percent changes was done by an unpaired $t$-test. Analysis of covariance was used to adjust for the baseline values of urinary parameters. Spearman correlation coefficients were used to assess the relationship between percent changes in blood pressure and in renal parameters. All statistical computations were performed using Stata Release 8.0 (Stata Corporation, College Station, TX, USA).

\section{RESULTS}

\section{Baseline characteristics}

A total of 194 patients were enrolled and randomized to one of the two doses: 95 patients were in the 80 -mg group and 99 patients in the 160 -mg group (Figure 1). However, five patients did not start medication because they did not meet study criteria $(n=3)$, withdrew informed consent $(n=1)$ or had no baseline visit $(n=1)$. Of the 189 patients who started the medication (92 in the low-dose group and 97 in the high-dose group), eight were excluded due to lack of follow-up visits $(n=2)$, discontinuation of treatment due to adverse effects before 12 weeks $(n=2)$ and failure to submit blood and urine sampling at baseline $(n=4)$. Thus, 181 patients remained in the efficacy analysis.

The baseline characteristics of the patients in the efficacy analysis are shown in Table 1. There were no significant differences in the ratio of men to women, smoking habits, alcohol consumption or comorbid conditions (diabetes mellitus (DM), renal disease and coronary artery disease) between the 80 and $160-\mathrm{mg} \mathrm{day}^{-1}$ groups.

Calcium channel blockers were used by 47 patients $(53 \%)$ in the low-dose group and 35 patients $(38 \%)$ in the high-dose group, and the difference was nearly significant $(P=0.053)$. Four patients in the lowdose group and one in the high-dose group used $\beta$-blockers $(P=0.21)$, and only one in the high-dose group used $\alpha$-blockers $(P=1.00)$.

Furthermore, there was no significant difference between the two groups in terms of blood pressure, serum creatinine levels, or urinary $\beta 2 \mathrm{MG}$ excretion. Both urinary type IV collagen and UAE were statistically significantly greater in the $160-\mathrm{mg}$ group than in the $80-\mathrm{mg}$ group at the baseline measurements.

\section{Blood pressure}

Both systolic and diastolic blood pressure decreased to the same extent in the two groups (Table 2). In the $80-\mathrm{mg}$ group, means of systolic/diastolic blood pressure levels were $156 / 87 \mathrm{~mm} \mathrm{Hg}$ at baseline, 136/76 mm Hg at week 12 and $137 / 76 \mathrm{~mm} \mathrm{Hg}$ at week 24 . 


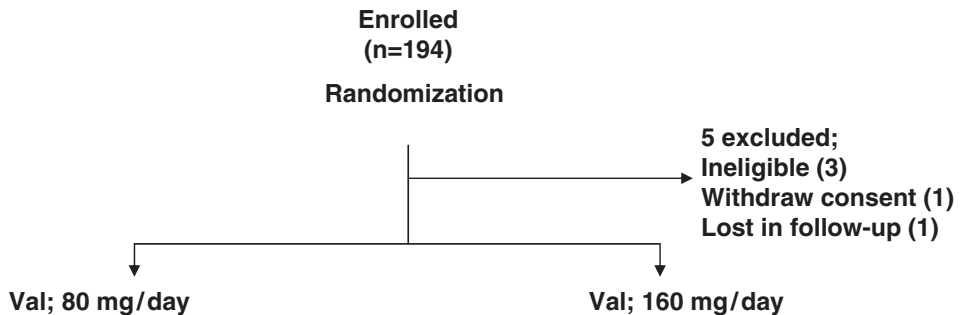

$\begin{array}{cc}\begin{array}{c}\text { Received study medication (safety population) } \\ (\mathrm{n}=92)\end{array} & \begin{array}{c}\text { Received study medication (safety population) } \\ (\mathrm{n}=97)\end{array} \\ \begin{array}{c}\text { Discontinued }(\mathrm{n}=3) \\ \text { Measurements error (1) }\end{array} & \begin{array}{c}\text { Discontinued }(\mathrm{n}=5) \\ \text { Measurements error }(3)\end{array} \\ \text { Last seen at } 2 \text { months (1) } & \text { Last seen at } 2 \text { months (1) } \\ \text { AE before } 6 \text { months (1) } & \text { AE before } 6 \text { months (1) } \\ \vdots & \vdots \\ 24 \text { weeks of follow-up (effectiveness population) } 24 \text { weeks of follow-up (effectiveness population) } \\ (n=89)\end{array}$

Figure 1 The design of the study and patient recruitment, including dose escalation in the 160-mg group.

Table 1 Characteristics of the study subjects used in efficacy analysis

\begin{tabular}{|c|c|c|c|}
\hline \multirow[b]{2}{*}{ Characteristic } & \multicolumn{2}{|c|}{ Dose $\left(m g\right.$ day $\left.^{-1}\right)$} & \multirow[b]{2}{*}{ P-value } \\
\hline & $80(n=89)$ & $160(n=92)$ & \\
\hline Males, $n(\%)$ & $40(44.9)$ & $40(43.5)$ & 0.88 \\
\hline Age (years) & $65.6(11.6)$ & $64.3(12.9)$ & 0.47 \\
\hline Height $(\mathrm{cm})$ & $157.9(7.9)$ & $156.5(9.5)$ & 0.29 \\
\hline Body weight (kg) & $60.4(9.0)$ & $60.6(12.4)$ & 0.88 \\
\hline Smoking, $n(\%)$ & $22(24.7)$ & $18(19.6)$ & 0.48 \\
\hline Alcohol use, $n(\%)$ & $36(40.4)$ & $34(37.0)$ & 0.65 \\
\hline \multicolumn{4}{|l|}{ Comorbid condition, $n(\%)$} \\
\hline Diabetes mellitus & $22(24.7)$ & $31(33.7)$ & 0.20 \\
\hline Renal disease & $5(5.6)$ & $4(4.4)^{b}$ & 0.75 \\
\hline Coronary heart disease & $5(5.6)$ & $4(4.3)$ & 0.74 \\
\hline Heart failure & $2(2.2)$ & $2(2.2)$ & 1.00 \\
\hline Stroke & $2(2.2)$ & $3(3.3)$ & 1.00 \\
\hline Dyslipidemia & $39(43.8)$ & $41(44.6)$ & 1.00 \\
\hline Use of other drugs, $n(\%)$ & $71(79.8)$ & $67(72.8)$ & 0.30 \\
\hline Systolic blood pressure $(\mathrm{mm} \mathrm{Hg})$ & $155.6(10.1)$ & $155.1(10.3)$ & 0.74 \\
\hline Diastolic blood pressure $(\mathrm{mm} \mathrm{Hg})$ & $86.6(10.6)$ & $87.6(9.7)$ & 0.51 \\
\hline Pulse (beats per min) & $73.3(8.5)$ & $75.4(10.5)^{\mathrm{b}}$ & 0.14 \\
\hline Serum BUN (mg per $100 \mathrm{ml}$ ) & $15.2(4.1)$ & $14.3(3.4)$ & 0.10 \\
\hline Serum creatinine $(\mathrm{mg} \text { per } 100 \mathrm{ml})^{\mathrm{c}}$ & $0.72(0.61-0.84)$ & $0.68(0.59-0.80)$ & 0.44 \\
\hline Urinary type IV collagen ( $\mu \mathrm{g}$ per $\mathrm{g} \mathrm{Cr})^{c}$ & $4.2(2.7-7.7)^{d}$ & $5.5(3.7-7.9)$ & 0.01 \\
\hline Urinary albumin (mg per $\mathrm{g} \mathrm{Cr})^{\mathrm{c}}$ & $21.2(11.2-54.0)$ & $34.5(16.6-73.2)$ & 0.05 \\
\hline Urinary $\beta_{2}$ microglobulin $(\mu \mathrm{g} \text { per } \mathrm{g} \mathrm{Cr})^{\mathrm{c}}$ & c $160(85-270)$ & $167(106-332)$ & 0.25 \\
\hline
\end{tabular}

Abbreviation: BUN, blood urea nitrogen.

Means (standard deviations) unless otherwise specified.

aBased on $t$-test for the comparison of means and Fisher's exact test for the comparison of proportions, unless otherwise specified.

${ }^{\mathrm{b}} n=91$ due to missing information.

"Median (interquartile range) with Wilcoxon rank sum test for the between-group comparison.

$n=88$ because of no measurement.

The corresponding values in the high-dose group $\left(160 \mathrm{mg} \mathrm{day}^{-1}\right)$ were $155 / 88,137 / 77$ and $137 / 76 \mathrm{~mm} \mathrm{Hg}$, respectively.

\section{Laboratory measurements}

Table 3 summarizes mean values, at baseline and 12 and 24 weeks after treatment, of serum BUN and creatinine levels and urinary excretion
Table 2 Means (s.e.) of blood pressure at baseline, 12 weeks and 24 weeks of treatment

\begin{tabular}{lrrrrrrr}
\hline & & \multicolumn{9}{c}{80} & & \multicolumn{2}{c}{160} & \\
Variable & Week & $\mathrm{N}$ & Mean (s.e.) & $\mathrm{N}$ & Mean (s.e.) & P-value \\
\hline \multirow{2}{*}{ SBP } & 0 & 89 & $155.6(1.1)$ & 92 & $155.1(1.1)$ & 0.74 \\
& 12 & 86 & $136.5(1.2)$ & 89 & $136.9(1.3)$ & 0.82 \\
& 24 & 83 & $137.4(1.2)$ & 91 & $137.1(1.2)$ & 0.89 \\
DBP & 0 & 89 & $86.6(1.1)$ & 92 & $87.6(1.0)$ & 0.51 \\
& 12 & 86 & $76.0(1.0)$ & 89 & $76.6(1.1)$ & 0.69 \\
& 24 & 83 & $76.3(1.1)$ & 91 & $76.5(1.0)$ & 0.89 \\
\hline
\end{tabular}

Abbreviations: DBP, diastolic blood pressure; SBP, systolic blood pressure.

of type IV collagen, albumin and $\beta 2 \mathrm{MG}$. Serum levels of BUN and creatinine did not change during the treatment, and there was no significant difference between the two dosing groups.

None of the urinary parameters showed a statistically significant difference between the two groups during treatment (Table 3). When the initial values were adjusted for the baseline difference, the magnitude by which UAE decreased during the treatment period was almost the same in the low- and high-dose groups (Table 4). Both groups showed a statistically significant 35\% decrease in UAE after 24 weeks of treatment. Urinary $\beta 2 \mathrm{MG}$ decreased significantly by $22 \%$ at 12 weeks and $17 \%$ at 24 weeks in the high-dose group, whereas the decrease in the low-dose group ( $13 \%$ at both 12 and 24 weeks) was not statistically significant. Urinary excretion of type IV collagen showed moderately statistically non-significant decreases at 12 and 24 weeks in both groups, although the decreases were greater at 24 weeks than at 12 weeks.

\section{Correlation between changes of blood pressure and urinary} markers

Changes of blood pressure were not related to changes in type IV collagen, albumin or $\beta 2 \mathrm{MG}$ at either 12 or 24 weeks of treatment. For instance, the Spearman correlation coefficients of the percent change of the systolic blood pressure with type IV collagen, albumin and $\beta 2 \mathrm{MG}$ at week 24 were $0.09,0.00$ and 0.04 , respectively. 
Table 3 Means (95\% confidence intervals) of renal function markers

\begin{tabular}{|c|c|c|c|c|c|c|}
\hline \multirow[b]{2}{*}{ Parameter } & \multirow[b]{2}{*}{ Week } & \multicolumn{2}{|c|}{$80 \mathrm{mg} \mathrm{day}^{-1}$} & \multicolumn{2}{|c|}{$160 \mathrm{mg} \mathrm{day}^{-1}$} & \multirow[b]{2}{*}{ P-value } \\
\hline & & $\mathrm{n}$ & Mean $(95 \% \mathrm{Cl})$ & $n$ & Mean $(95 \% \mathrm{Cl})$ & \\
\hline \multirow[t]{3}{*}{ Serum BUN (mg per $100 \mathrm{ml}$ ) } & 0 & 89 & $15.2(14.3-16.1)$ & 92 & $14.3(13.6-15.0)$ & 0.10 \\
\hline & 12 & 86 & $15.8(14.8-16.8)$ & 89 & $15.4(14.6-16.2)$ & 0.55 \\
\hline & 24 & 83 & $15.8(14.6-16.7)$ & 91 & $15.5(14.7-16.3)$ & 0.73 \\
\hline \multirow[t]{3}{*}{ Serum creatinine $(\mathrm{mg} \text { per } 100 \mathrm{ml})^{\mathrm{b}}$} & 0 & 89 & $0.72(0.68-0.76)$ & 92 & $0.70(0.67-0.74)$ & 0.51 \\
\hline & 12 & 86 & $0.74(0.69-0.78)$ & 89 & $0.72(0.69-0.76)$ & 0.67 \\
\hline & 24 & 83 & $0.73(0.68-0.77)$ & 91 & $0.72(0.68-0.76)$ & 0.82 \\
\hline \multirow[t]{3}{*}{ Urinary type IV collagen ( $\mu \mathrm{g}$ per $\mathrm{g} \mathrm{Cr})^{\mathrm{b}}$} & 0 & $88^{c}$ & $4.4(3.7-5.2)$ & 92 & $5.6(4.8-6.4)$ & 0.03 \\
\hline & 12 & 85 & $4.4(3.8-5.1)$ & 89 & $5.0(4.4-5.7)$ & 0.17 \\
\hline & 24 & 82 & $4.2(3.6-4.9)$ & 91 & $4.8(4.2-5.6)$ & 0.16 \\
\hline \multirow[t]{3}{*}{ Urinary albumin (mg per $\mathrm{g} \mathrm{Cr})^{\mathrm{b}}$} & 0 & 89 & $27.2(20.2-36.7)$ & 92 & $35.0(26.6-45.9)$ & 0.22 \\
\hline & 12 & 86 & $22.0(16.7-29.1)$ & 89 & $24.3(19.2-30.9)$ & 0.59 \\
\hline & 24 & 83 & $17.5(13.1-23.4)$ & 91 & $21.8(16.8-28.3)$ & 0.27 \\
\hline \multirow[t]{3}{*}{ Urinary $\beta_{2}$ microglobulin ( $\mu \mathrm{g}$ per $\left.\mathrm{g} \mathrm{Cr}\right)^{\mathrm{b}}$} & 0 & 89 & $171.2(134.6-217.8)$ & 92 & $199.1(157.5-251.7)$ & 0.37 \\
\hline & 12 & 86 & $155.4(122.3-197.5)$ & 89 & 154.1 (121.6-195.3) & 0.96 \\
\hline & 24 & 83 & 150.6 (118.3-191.7) & 91 & 161.9 (132.0-198.5) & 0.65 \\
\hline
\end{tabular}

Abbreviations: BUN, blood urea nitrogen; $\mathrm{Cl}$, confidence interval.

Means ( $95 \%$ confidence intervals) of renal function markers at baseline, 12 weeks and 24 weeks of treatment by daily dose of valsartan.

aBased on $t$-test for the between-group comparison.

${ }^{b}$ Geometric means ( $95 \%$ confidence interval).

'One subjects was excluded because of missing value at baseline.

Table 4 Adjusted mean percent changes from the baseline in urinary markers of renal function at 12 and 24 weeks of treatment by daily dose ${ }^{a}$

\begin{tabular}{|c|c|c|c|c|c|c|}
\hline \multirow[b]{2}{*}{ Parameter } & \multirow[b]{2}{*}{ Week } & \multicolumn{2}{|r|}{$80 \mathrm{mgday}^{-1}$} & \multicolumn{2}{|r|}{160 mg day $^{-1}$} & \multirow[b]{2}{*}{ P-value } \\
\hline & & $n$ & Mean $(95 \% \mathrm{Cl})$ & $\mathrm{n}$ & Mean $(95 \%$ Cl) & \\
\hline \multirow[t]{2}{*}{ Urinary type IV collagen ( $\mu$ g per g Cr) } & 12 & 85 & $-5.6(-16.1 ; 6.2)$ & 89 & $-5.1(-15.4 ; 6.5)$ & 0.95 \\
\hline & 24 & 82 & $-10.4(-21.5 ; 2.2)$ & 91 & $-8.1(-18.9 ; 4.2)$ & 0.78 \\
\hline \multirow[t]{2}{*}{ Urinary albumin ( $\mu \mathrm{g}$ per $\mathrm{g} \mathrm{Cr}$ ) } & 12 & 86 & $-23.6(-35.7 ;-9.3)$ & 89 & $-28.2(-39.3 ;-14.9)$ & 0.62 \\
\hline & 24 & 83 & $-34.9(-47.2 ;-19.8)$ & 91 & $-35.3(-47.0 ;-21.0)$ & 0.97 \\
\hline \multirow[t]{2}{*}{ Urinary $\beta_{2}$ microglobulin ( $\mu$ g per g $\mathrm{Cr}$ ) } & 12 & 86 & $-12.9(-27.0 ; 4.0)$ & 89 & $-21.9(-34.4 ;-7.1)$ & 0.39 \\
\hline & 24 & 83 & $-13.4(-26.5 ; 2.0)$ & 91 & $-16.7(-28.7 ;-2.6)$ & 0.74 \\
\hline
\end{tabular}

Abbreviation: $\mathrm{Cl}$, confidence interval.

aBased on analysis of covariance with control for the baseline value.

\section{Adherence to drug use}

Adherence to drug use was good in 171 of 176 patients $(97.2 \%)$ at 12 weeks and 165 of 174 patients $(94.8 \%)$ at 24 weeks, and no significant difference was noted between the 80 and $160-\mathrm{mg} \mathrm{day}^{-1}$ groups. Of the 92 patients in the high-dose group, 61 patients started at a dose of $160 \mathrm{mg} \mathrm{day}^{-1}$ from the beginning of the treatment, and 27 patients started at a dose of $80 \mathrm{mgday}^{-1}$ and increased the dose to $160 \mathrm{mg} \mathrm{day}^{-1}$ after a median of 14 days (ranging from 7 to 111 days) of the treatment period. No dose increase was reported in the remaining four patients.

\section{Adverse events}

Four cases of serious adverse events were noted in the $80-\mathrm{mg} \mathrm{day}^{-1}$ group, including adult $\mathrm{T}$ cell type leukemia, unstable angina pectoris, cardiogenic stroke and bone fracture. No such serious adverse events were observed in the 160 -mg day ${ }^{-1}$ group.

Adverse events occurred in $22(24.7 \%)$ and 15 patients $(16.3 \%)$ in the 80 - and $160-\mathrm{mg} \mathrm{day}^{-1}$ groups, respectively, including mild elevation of aspartate aminotransferase, alanine aminotransferase, lactic dehydrogenase and creatinine ( $\leqslant 3$ times of baseline readings). Discontinuation of valsartan was only necessary in the abovementioned four patients with serious adverse events, and termination of valsartan was not necessary in the remaining patients.

\section{DISCUSSION}

Two major findings in this study were that both low-dose valsartan treatment regimens $\left(80 \mathrm{mg} \mathrm{day}^{-1}\right)$ and high-dose treatment regimens $\left(160 \mathrm{mg} \mathrm{day}^{-1}\right)$ resulted in a blood pressure decrease to a similar level. There was no dose-dependent difference or substantial reduction of UAE of the same magnitude with either low- or high-dose valsartan therapy. Notably, a significant decrease in urinary excretion of $\beta 2 \mathrm{MG}$ was observed only in the high-dose group, but not in the low-dose group. The degree of decrease in $\beta 2 \mathrm{MG}$ from baseline was not significantly different between the two groups.

It is rather surprising that the reduction in blood pressure did not differ secondary to the different doses of valsartan, because it has generally been known that ARBs decrease blood pressure in a dosedependent manner. ${ }^{7-10}$ The blood pressure at baseline did not differ in the low-dose $v$ s. high-dose groups. Therefore, a more frequent use of calcium channel blockers at baseline in the low-dose group may be a possible explanation for a reduction of blood pressure in the low-dose group similar to that in the high-dose group. In addition, although 61 
patients in the high-dose group did take a high dose at the beginning of the treatment period, 27 patients followed a high-dose regimen after 2 weeks of the low-dose treatment period, and four patients stayed at $80 \mathrm{mg}$ though the treatment period. Thus, this finding suggests that valsartan does not necessarily exert a dose-dependent effect on lowering blood pressure, at least in the range of 80$160 \mathrm{mgday}^{-1}$, in the present cohort of patients. The changes in urinary parameters were not measurably correlated with a reduction in blood pressure. Therefore, the above findings about urinary parameters may suggest that a reno-protective effect of valsartan is independent of the drug's effect on lowering blood pressure.

The reason for why we did not observe a dose-dependent difference in UAE is not clear. It has been previously reported that a single dose of valsartan can have a reno-protective effect in Japanese populations. In the SMART study, ${ }^{19}$ a dose of valsartan $\left(80 \mathrm{mg} \mathrm{day}^{-1}\right)$, as compared with $5 \mathrm{mg} \mathrm{day}^{-1}$ of amlodipine, decreased micro-albuminuria significantly in 153 patients with type $2 \mathrm{DM}$. The $\mathrm{HARB}^{20}$ study compared the effect of valsartan ( $160 \mathrm{mg}$ daily) and $12 \mathrm{mg}$ of candesartan daily in 55 hypertensive patients by changing over the drugs. The HARB study disclosed a significant reduction in urinary protein excretion (UPE) by both valsartan and candesartan; however, there was no significant reduction in UAE for the 44 patients studied. Sato et al. ${ }^{21}$ also reported that both ACEIs and ARB (candesartan) decreased UAE; however, urinary excretion of type IV collagen was decreased by candesartan, but not by ACEIs.

Thus, no direct dose-effect comparison has been studied, such as this study's comparison of 80 vs. $160 \mathrm{mg}$ valsartan daily. This comparative study was the first that compared two different doses of valsartan on renal function. Urinary $\beta 2 \mathrm{MG}$ and UAE have been known to be surrogate markers of renal function measured by glomerular filtration rate (GFR) and proximal tubular re-absorption. According to a recent review, UAE depends on the balance of glomerular filtration, retrieval and degradative pathways in the proximal tubule, but not on charge effect. ${ }^{22}$ The molecular weights of albumin and $\beta 2 \mathrm{MG}$ are roughly 60000 and 11800 , whereas that of type IV collagen is much larger-estimated at more than 540000. Therefore, the mechanisms of urinary excretion of albumin and $\beta 2 \mathrm{MG}$, which are rather small molecules compared with type IV collagen, may be different from that of type IV collagen.

It was recently suggested that urinary $\beta 2 \mathrm{MG}$ is an important prognostic marker in patients with membranous nephropathy. ${ }^{23,24}$ Although the mechanism of proximal tubule injury between idiopathic membranous nephropathy and hypertension may not be the same, $\beta 2 \mathrm{MG}$ may also be used as a surrogate marker of renal function in those with hypertension. If so, although the present findings were not conclusive, they may be evidence of the dose-dependent renoprotective effect of ARBs.

Regarding urinary excretion of type IV collagen, we did not find any significant decrease in either the 80 - or the $160-\mathrm{mg} \mathrm{day}^{-1}$ valsartan group. Ogawa et al..$^{25}$ reported that ARBs (candesartan and valsartan) reduced oxidative stress and inflammation in 66 diabetic patients, resulting in a decrease in UAE and type IV collagen excretion. They also noted a significant correlation between the reduction in urinary 8-epiprostaglandin F2 $\alpha$ and 8-hydroxydeoxyguanosine levels, as well as a reduction in urinary excretion of albumin and type IV collagen. Sato et al. ${ }^{21}$ also reported a decrease in urinary excretion of type IV collagen secondary to candesartan therapy. The reason for the discrepancy between our results and those of Ogawa et al. ${ }^{25}$ and Sato et al. ${ }^{21}$ regarding type IV collagen is not clear. We did not measure urinary excretion of oxidative stress markers, nor was our entire patient population diabetic. Importantly, Takizawa et al. ${ }^{26}$ reported urinary excretion of type IV collagen in the absence of UAE, and the progression of nephropathy increased the excretion of type IV collagen. Banu et al. ${ }^{27}$ also reported urinary excretion of type IV collagen in those with normo-albuminuria. Taken together, it is still debatable whether UAE, $\beta 2 \mathrm{MG}$ or type IV collagen is the most sensitive marker of renal injury, as measured by urine secretion, in patients with hypertension. This question requires further study in patients with hypertension.

\section{Clinical implications}

In this study, although UAE is almost equally decreased by both 80 and $160 \mathrm{mg}$ valsartan daily, $\beta 2 \mathrm{MG}$ excretion was decreased significantly only in the high-dose group under the conditions of equal blood pressure level. Therefore, a high dose of valsartan may leave the door open for further study on reno-protection in the Japanese population. The high-dose group did not show increased adverse effects, including serum potassium level.

These adverse effects of ARBs, including hyperkalemia, should be carefully monitored in patients treated with high-dose valsartan and possibly other ARBs. Finally, the importance of addressing and treating potential risks for the development of chronic kidney disease, such as DM and hypertension must also be considered.

\section{Limitations}

Although the patients were randomly allocated to one of the two regimens, urinary type IV collagen and albumin excretion at baseline were greater in the high-dose group. As other parameters, such as blood pressure and serum creatinine at baseline, did not show any difference between the two groups, it is unlikely that random allocation was deliberately distorted with respect to the severity of albuminuria. Nevertheless, unequal baseline values between the two groups cause difficulty in interpretation of this findings, as discussed above. The UAE level was expressed in units of $\mathrm{mg}$ per $\mathrm{g} \bullet \mathrm{Cr}$ in this study instead of total albumin excretion per day, so the patients enrolled in the study may well have both micro- and macro-albuminuria, which were analyzed together. ${ }^{28}$

\section{Conclusion}

This study showed that both 80 and $160 \mathrm{mg}$ of valsartan daily lowered blood pressure and UAE to similar levels with no significant difference. Furthermore, high-dose valsartan ( $160 \mathrm{mg}$ daily) reduced urinary excretion of $\beta 2 \mathrm{MG}$. Direct comparison of low-dose and high-dose therapy did not show a significant difference. The significant predominant reduction of $\beta 2 \mathrm{MG}$ only in the high-dose group, however, may suggest dose-dependent reno-protection independent of attained blood pressure levels.

Further study with more patients is warranted.

\section{ACKNOWLEDGEMENTS}

We thank the following doctors who participated in the study: Y Ikeda, T Inou, M Tanaka, K Yamamoto, S Matano, S Nobe, H Ozaki, Y Ohshima, A Yoshimura, T Ooie, H Ono, S Ishida, K Shinozaki, K Yano, M Saito, N Abe, K Okamoto, H Toshimori, S Kariya, M Ageta, T Hashino, Y Kamogawa, S Suzuki, K Kurobe, M Kojima, R Migita, H Koga, S Ikeda, A Takahashi, and Y Uchida. This study was funded by a clinical research grant from the International University of Health and Welfare, Tochigi, Japan.

1 Lewis EJ, Hunsicker LG, Clarke WR, Berl T, Pohl MA, Lewis JB, Ritz E, Atkins RC, Rohde R, Raz I, Collaborative Study Group. Renoprotective effect of the angiotensinreceptor antagonist irbesartan in patients with nephropathy due to type 2 diabetes. N Engl J Med 2001; 345: 851-860. 
2 Dahlöf B, Devereux RB, Kjeldsen SE, Julius S, Beevers G, de Faire U, Fyhrquist F, Ibsen $\mathrm{H}$, Kristiansson K, Lederballe-Pedersen O, Lindholm LH, Nieminen MS, Omvik P, Oparil $\mathrm{S}$, Wedel H, LIFE Study Group. Cardiovascular morbidity and mortality in the Losartan Intervention For Endpoint reduction in hypertension study (LIFE): a randomized trial against atenolol. Lancet 2002; 359: 995-1003.

3 Barnett AH, Bain SC, Bouter P, Karlberg B, Madsbad S, Jervell J, Mustonen J, Diabetics Exposed to Telmisartan and Enalapril Study Group. Angiotensin-receptor blockade versus converting-enzyme inhibition in type 2 diabetes and nephropathy. $N$ Engl J Med 2004; 351: 1952-1961.

4 Julius S, Kjeldsen SE, Weber M, Brunner HR, Ekman S, Hansson L, Hua T, Laragh J, McInnes GT, Mitchell L, Plat F, Schork A, Smith B, Zanchetti A, VALUE trial group. Outcomes in hypertensive patients at high cardiovascular risk treated with regimens based on valsartan or amlodipine: the VALUE randomized trial. Lancet 2004; 363 : 2022-2031.

5 Ogihara T, Nakao K, Fukui T, Fukiyama K, Fujimoto A, Ueshima K, Oba K, Shimamoto K, Matsuoka H, Saruta T, CASE-J Trial Group. The optimal target blood pressure for antihypertensive treatment in the Japanese elderly patients with high-risk hypertension: a subanalysis of the Candesartan Antihypertensive Survival Evaluation in Japan (CASEJ) trial. Hypertens Res 2008; 31: 1595-1601.

6 Scott LJ, McCormack PL. Olmesartan medoxomil: a review of its use in the management of hypertension. Drugs 2008; 68: 1239-1272.

7 Oparil S, Dyke S, Harris F, Kief J, James D, Hester A, Fitzsimmons S. The efficacy and safety of valsartan compared with placebo in the treatment of patients with essential hypertension. Clin Therp 1996; 18: 797-810.

8 Neutel J, Weber M, Pool J, Smith D, Fitzsimmons S, Chiang YT, Gatlin M. Valsartan, a new angiotensin II antagonist: antihypertensive effects over 24 hours. Clin Ther 1997; 19: 447-458.

9 Giles TD, Oparil S, Silfani TN, Wang A, Walker JF. Comparison of increasing doses of olmesartan medoxomil, losartan potassium, and valsartan in patients with essential hypertension. J Clin Hypertens (Greenwich) 2007; 9: 187-195.

10 Pool JL, Glazer R, Chiang YT, Gatlin M. Dose-response efficacy of valsartan, a new angiotensin II receptor blocker. J Hum Hypertens 1999; 13: 275-281.

11 Brenner BM, Cooper ME, de Zeeuw D, Keane WF, Mitch WE, Parving HH, Remuzzi G, Snapinn SM, Zhang Z, Shahinfar S, RENAAL Study Investigators. Effects of losartan on renal and cardiovascular outcomes in patients with type 2 diabetes and nephropathy. N Engl J Med 2001; 345: 861-869.

12 Viberti G, Wheeldon NM, MicroAlbuminuria Reduction with VALsartan (MARVAL) Study Investigators. Microalbuminuria reduction with valsartan in patients with type 2 diabetes mellitus: a blood pressure-independent effect. Circulation 2002; 106 672-678

13 Galle J. Reduction of proteinuria with angiotensin receptor blockers. Nat Clin Pract Cardiovas Med 2008; 5(Suppl 1): S36-S43.

14 Hirsch S. An update on proteinuric chronic kidney disease: the dual-goal approach. Cleve Clinic J Med 2008; 75: 705-713.

15 Suzuki K, Souda S, Ikarashi T, Kaneko S, Nakagawa O, Aizawa Y. Renoprotective effects of low-dose valsartan in type 2 diabetic patients with diabetic nephropathy. Diabetes Res Clin Prac 2002; 57: 179-183.

16 Hollenberg NK, Parving HH, Viberti G, Remuzzi G, Ritter S, Zelenkofske S, Kandra A Daley WL, Rocha R. Albuminuria response to very high-dose valsartan in type 2 diabetes mellitus. J Hypertens 2007; 25: 1921-1926.

17 Schmieder RE, Klingbeil AU, Fleischmann EH, Veelken R, Delles C. Additional antiproteinuric effect of ultrahigh dose candesartan: a double-blind, randomized, prospective study. J Am Soc Nephrol 2005; 16: 3038-3045.

18 Tominaga N, Robert A, Izuhara Y, Ohtomo S, Dan T, Chihara K, Kurokawa K, Van Ypersele de Strihou C, Miyata T. Very high doses of valsartan provide renoprotection independently of blood pressure in a type 2 diabetic nephropathy rat model. Nephrology (Carlton) 2009; 14: 581-587.
19 Shiga Microalbuminuria Reduction Trial (SMART) GroupUzu T Sawaguchi M Maegawa $\mathrm{H}$, Kashiwagi $\mathrm{A}$. Reduction of microalbuminuria in patients with type 2 diabetes: the Shiga Microalbuminuria Reduction Trial (SMART). Diabetes Care 2007; 30: 1581-1583.

20 Ohishi M, Takagi T, Ito N, Tatara Y, Hayashi N, Shiota A, Iwamoto Y, Katsuya T, Rakugi $\mathrm{H}$, Ogihara $\mathrm{T}$. Renal protective effect in hypertensive patients: the high doses of angiotensin II receptor blocker (HARB) study. Hypertens Res 2007; 30: 1187-1192.

21 Sato A, Tabata M, Hayashi K, Satuta T. Effects of the angiotensin II type 1 antagonists candesartan, compared with angiotensin-converting enzyme inhibitors, on the urinary excretion of albumin and type IV collagen in patients with diabetic nephropathy. Clin Exp Nephrol 2003; 7: 215-220.

22 Comper WD, Hilliard LM, Nikolic-Paterson DJ, Russo LM. Disease-dependent mechanisms of albuminuria. Am J Physiol Renal Physiol 2008; 295: F1589-F1600.

23 Branten AJW, du Buf-Vereijken PW, Klasen IS, Bosch FH, Feith GW, Hollander DA, Wetzels JF. Urinary excretion of $\beta 2$-microglobulin and IgG predict prognosis in idiopathic membranous nephropathy: a validation study. J Am Soc Nephrol 2005. 16: 169-174.

24 Hofstra JM, Deegens JKJ, Willems HL, Wetzels JFM. Beta-2-microglobulin is superior to $\mathrm{N}$-acetyl-beta-glucosaminidase in predicting prognosis in idiopathic membranous nephropathy. Nephrol Dial Transplant 2008; 23: 2546-2551.

25 Ogawa S, Mori T, Nako K, Kato T, Takeuchi K, Ito S. Angiotensin II type 1 receptor blockers reduce urinary oxidative stress markers in hypertensive diabetic nephropathy. Hypertension 2006; 47: 699-705.

26 Takizawa H, Satoh T, Kurusu A, Hishiki T, Shike T, Gohda T, Maeda A, Makita Y, Suzuki $S$, Fukui M, Tomino Y. Increase of urinary type IV collagen in normoalbuminuric patients with impaired glucose tolerance. Nephron 1998; 79: 474-475.

27 Banu N, Hara H, Okamura M, Egusa G, Yamakido M. Urinary excretion of type IV collagen and laminin in the evaluation of nephropathy in NIDDM: comparison with urinary albumin and markers of tubular dysfunction and/or damage. Diabetes Res Clin Pract 1995; 29: 57-67.

28 Ruggenenti P, Gaspari F, Perna A, Remuzzi G. Cross sectional longitudinal study of spot morning urine protein: creatinine ratio, 24 hour urine protein excretion rate, glomerular filtration rate, and end stage renal failure in chronic renal disease in patients without diabetes. BMJ 1998; 316: 504-509.

\section{APPENDIX}

The study's Executive Committee consisted of J Sasaki (Principal Investigator and Member of Protocol Committee), International University of Health and Welfare Graduate School of Public Health Medicine, Fukuoka, Japan; T Saikawa (member of Protocol Committee), Oita University, Oita, Japan; T Kuribayashi, Koga General Hospital, Miyazaki; S Biro (member of Protocol Committee), Tsukasa Hospital, Kagoshima, Japan; K Yamamoto (member of the Safety Monitoring Committee), Takagi Hospital, Fukuoka, Japan; S Ikeda, Second Department of Internal Medicine, Nagasaki University, Nagasaki, Japan. The Safety Monitoring Committee consisted of N Okabe, Ayasugi Building Clinic, Fukuoka, Japan. The head of the Registration Center and Data Center was S Kono (member of Protocol Committee), Kyushu University Faculty of Medical Sciences, Fukuoka, Japan. 